\title{
PODER JUDICIÁRIO E REGIME AUTORITÁRIO: DEMOCRACIA, HISTÓRIA CONSTITUCIONAL E PERMANÊNCIAS AUTORITÁRIAS
}

\section{JUDICIARY AND AUTHORITARIAN REGIME: DEMOCRACY, CONSTITUTIONAL HISTORY AND AUTHORITARIAN STAYS}

\author{
Vanessa Dorneles Schinke* \\ José Carlos Moreira da Silva Filho**
}

\begin{abstract}
RESUMO
O trabalho analisa procedimentos adotados pela ditadura civil-militar brasileira (1964-1985) em relação ao Poder Judiciário, e tem como objeto identificar estratégias utilizadas pelo Judiciário para amenizar impressões de descontinuidades ou anormalidades institucionais. Nesse intuito, faz a análise a partir de dois eixos interpretativos: das permanências autoritárias e dos discursos criados para sustentar o projeto autoritário. Diante da legalidade autoritária, defende que o Poder Judiciário adotou a teoria do direito como fato, no intuito de obscurecer a ruptura com o Estado de direito, misturando sem qualquer cerimônia Atos Institucionais, a Constituição outorgada e a legislação anterior, produzida em período democrático. Analisando a doutrina de segurança nacional, o artigo identifica a similitude entre a narrativa construída pelo Judiciário brasileiro e o modelo conservador latino-americano, e traz elementos da história constitucional brasileira, identificando repetições históricas em relação aos papéis desempenhados pelo Judiciário em diferentes contextos autoritários. Por fim, aponta para algumas continuidades autoritárias do Judiciário brasileiro no período pós-ditatorial.
\end{abstract}

\section{PALAVRAS-CHAVE}

Poder Judiciário. Regime autoritário. Democracia. Permanências autoritárias.

\begin{abstract}
This paper analyzes the procedures adopted by the civilian-military dictatorship in Brazil (19641985) in relation to the judiciary. Its corporate purpose is to identify strategies used by the judiciary in order to alleviate impressions of discontinuities or institutional abnormalities. To that end, it makes the analysis from two interpretive themes: the authoritarian stays and speeches created to support the authoritarian project. In the face of authoritarian legality, it argues that the judiciary has

\footnotetext{
* Doutora em Direito pela Pontifícia Universidade Católica do Rio Grande do Sul (PUCRS), com período sanduíche na King's College London (KCL/Reino Unido). Mestre em Direito pela Universidade de Brasília (UnB). Integrante do Grupo de Estudos Direito à Verdade e à Memória e Justiça de Transição (CNPq) e do Grupo de Estudos sobre Internacionalização do Direito e Justiça de Transição - IDEJUST (São Paulo, SP, Brasil). E-mail: vanessa.schinke@gmail.com

** Doutor em Direito das Relações Sociais pela Universidade Federal do Paraná (UFPR). Mestre em Teoria e Filosofia do Direito pela Universidade Federal de Santa Catarina (UFSC). Bacharel em Direito pela Universidade de Brasília (UnB). Professor Adjunto do Programa de Pós-graduação em Ciências Criminais - Mestrado e Doutorado - e da Graduação em Direito da Faculdade de Direito da Pontifícia Universidade Católica do Rio Grande do Sul (PUCRS, Porto Alegre, RS, Brasil). Bolsista Produtividade em Pesquisa Nível 2 do CNPq. Conselheiro e Vice-Presidente da Comissão de Anistia do Ministério da Justiça. Coordenador do Grupo de Estudos CNPq Direito à Verdade e à Memória e Justiça de Transição. Membro-Fundador do Grupo de Estudos sobre Internacionalização do Direito e Justiça de Transição - IDEJUST.E-mail: josecarlosfilho@terra.com.br
}

Artigo elaborado com o apoio do Conselho Nacional de Desenvolvimento Científico e Tecnológico - CNPq. 
adopted the theory of law and fact in order to obscure the break with the rule of law, using without distinction Institutional Acts, an imposed Constitution and laws from the previous democratic period. By analyzing national security doctrine, it projects the similarity between the narrative constructed by the judiciary and the conservative Latin American model, and also brings elements of the Brazilian constitutional history, identifying historical repetitions in relation to the roles played by the judiciary in different authoritarian contexts. Finally, it points to some authoritarian continuities of the Brazilian judiciary in the post-dictatorial period.

\section{KEYWORDS}

Judiciary. Authoritarian regime. Democracy. Authoritarian stays.

SUMÁRIO: Introdução. 1 A implantação do regime autoritário e o Poder Judiciário. 2 A aplicação da legalidade autoritária. 3 O projeto constitucional autoritário. 4 Permanências e metamorfoses autoritárias do Judiciário no período pós-ditatorial. 5 Considerações Finais. Referências.

\section{INTRODUÇÃO}

Além de não ter definição nem usos canônicos, a expressão autoritarismo, por si só, não é suficiente para caracterizar o conteúdo de uma organização política. Frequentemente, signo é utilizado de forma marcadamente ideológica, a fim de designar, de forma bastante vaga, modelos de Estados centralizadores. Ainda assim, é possível identificar que a literatura associa o autoritarismo com governos excessivamente centralizadores, que colocam em segundo plano as instituições representativas (SANTOS, 2007, p. 282). Não raro, a usual consequência dessa composição de governo é o prejuízo aos direitos fundamentais.

O papel do Judiciário nas democracias tem sido pauta de inúmeros debates, desde a crítica ao positivismo jurisprudencial e à retomada do sentido do poder constituinte no Estado Constitucional (BERCOVICI, 2004, 2013) até o ativismo judicial (MAUS, 2000). De todo modo, nos contextos democráticos, o Judiciário limita atos dos representantes da soberania, por meio do controle de constitucionalidade, e, paralelamente, realiza um exercício contramajoritário, na defesa dos direitos fundamentais (GARGARELLA, 2007, p. 19), posicionando, por outro lado, o possível conflito entre uma acentuada judicialização da política e a prevalência da soberania popular.

Os modos e padrões de atuação do Poder Judiciário, assumidos em regimes autoritários, podem intervir na qualidade e na estrutura da atividade judicial em democracias, dando origem às chamadas permanências. Todavia, os movimentos desempenhados pelo Judiciário durante regimes autoritários ainda são nebulosos, em parte pela dificuldade ou pelo desinteresse de acesso aos arquivos, ou seja, às fontes primárias. Ainda assim, algumas pesquisas já realizadas nos permitem visualizar os paradoxos criados e estimulados durante ditaduras (AGUILAR, 2013). Um bom 
exemplo desses paradoxos é o manejo do poder legiferante pelos regimes autoritários: reservavamse o direito de alterar arbitrariamente as normas criadas pelo próprio poder de exceção e, concomitantemente, faziam questão de tê-las.

Desde a usurpação do poder pelas Forças Armadas, em 1976, na Argentina, o caos legislativo manifestou-se pela utilização aleatória das regras que, além de possuírem conteúdo arbitrário, não seguiam nenhuma rotina de publicação, contrariando normas básicas de hierarquia das leis e de processo legislativo. A Constituição foi reformada quando a edição de uma lei bastaria, leis foram publicadas para casos que exigiam decretos, manifestações estatutárias, legislativas ou meras manifestações de propósitos sem conteúdo jurídico foram denominadas “atas” e foram publicadas resoluções para conteúdos que requeriam a forma de decreto (GROISMAN, 2015, p. $50)$.

No Brasil, as Constituições de 1946 e de 1967 foram corriqueiramente alteradas por meio de emendas ou de atos institucionais. Barbosa (2010, p. 8) afirma que os atos institucionais alteraram regras do procedimento de emenda constitucional e, por mais de uma vez, modificaram a própria constituição, ao passo que as emendas constitucionais foram outorgadas em mais de uma oportunidade e chegaram a ser usadas para transpor comandos normativos veiculados em atos institucionais para o texto constitucional, em uma manifesta ambiguidade entre normalidade constitucional e medidas excepcionais. Casos como o do Brasil e da Argentina respaldam estudos que defendem ser comum que regimes autoritários usem a lei para reforçar seu poder, no intuito de tornar confusa a distinção entre regimes de fato e de direito (PEREIRA, 2010, p. 36).

O aprofundamento da reflexão sobre a instrumentalização arbitrária do direito nos regimes autoritários trouxe consigo o questionamento sobre os responsáveis pela sua aplicação. Essa indagação enfrenta, naturalmente, as funções exercidas pelo Judiciário. Embora esse questionamento tenha ganhado fôlego, as chaves de leitura que cada contexto autoritário oferece para as respostas ainda são nebulosas. Em busca de respostas para a manutenção do Judiciário pelos regimes autoritários, autores como Ginzburg (2003) entendem que, enquanto a correlação entre as forças políticas fosse equilibrada e conhecida, haveria certa motivação para a presença de tribunais superiores, no intuito de resolver conflitos e evitar bloqueios institucionais, no desempenho de uma clara função mediadora. Tal função não seria necessária em contextos em que a correlação de forças fosse clara e atingisse um patamar seguro de desigualdade para quem estivesse no poder, pois não seria razoável a assunção do risco de limitar as decisões com a presença de uma instituição com capacidade de frustrar a implantação do projeto autoritário. 
Situações como essas sugerem algumas incongruências: a manutenção do Judiciário em contextos incompatíveis com a democracia e a manutenção de espaços que possam limitar a atuação do regime autoritário. Apesar desse paradoxo, a história nos mostra que inúmeros regimes autoritários mantiveram seus Judiciários sem que isso representasse, necessariamente, impedimento à implementação de suas agendas.

Dentro da dimensão civil dos regimes autoritários latino-americanos, este artigo propõe-se a refletir sobre alguns movimentos que ocorreram no Judiciário brasileiro, especialmente na sua cúpula, a fim de identificar permanências dentro da sua narrativa constitucional e, assim, pensar nossa democracia.

\section{A IMPLANTAÇÃO DO REGIME AUTORITÁRIO E O PODER JUDICIÁRIO}

Em 1964, o primeiro ato legal autoritário teve o cuidado de suspender as garantias da vitaliciedade e da estabilidade e de afastar do controle jurisdicional os atos resultantes da nova ordem de exceção. O Judiciário brasileiro, desde então, limitar-se-ia ao exame de formalidades extrínsecas dos atos - inclusive da legalidade autoritária - vedada a apreciação dos fatos que motivassem sua aplicação, bem como da sua conveniência ou oportunidade (BRASIL, 1964, p. 3.193). Paradoxalmente, a decisão sobre a incidência ou não da cláusula de exclusão da apreciação judicial era realizada pelos próprios juízes, interpretando a legalidade autoritária diante dos casos concretos. Posteriormente, o Ato Institucional $\mathrm{n}^{0} 2$ determinou que os juízes federais fossem nomeados pelo Presidente da República (regra mantida até a Emenda de 1967) (BRASIL, 1965, p. 11.353).

Reposicionando o Judiciário brasileiro, inclusive sua cúpula, e a justiça comum (estadual e federal) dentro da organização burocrática autoritária, o Ato Institucional $n^{0} 2$ (AI-2) baseou-se em duas linhas de ação: a organização judiciária da justiça militar e a ampliação da sua competência para julgar civis acusados de crime contra a segurança nacional. O intuito era afastar da justiça comum o julgamento de casos que pudessem ter maior impacto na opinião pública.

O Supremo Tribunal Federal era, desde 1891, composto por 15 ministros. O Decreto $\mathrm{n}^{\mathrm{0}}$ 19.656/1931 - Ato do Governo Provisório - reduziu o número para onze. Em 1965, o AI-2 aumentou o número de ministros para dezesseis. A última alteração foi operada em 1969, pelo Ato Institucional $n^{\circ} 5$, que reduziu o número de ministros, novamente, para onze.

A alteração do número de ministros que compõem o principal tribunal do País e a realocação do Judiciário no aparato estatal em contextos autoritários são medidas que já haviam 
aparecido na partitura constitucional brasileira, especificamente em seus interstícios de rupturas institucionais. Após o Levante Comunista de 1935, por exemplo, o governo varguista adotou medidas para reprimir a oposição, tratando, desde logo, de criar o Tribunal de Segurança Nacional (TSN), instalado em 1936. Ao TSN competiria julgar, inicialmente, os envolvidos no Levante; no entanto, o órgão foi posteriormente utilizado para julgar indivíduos com base em distinções claramente ideológicas, bastando aos réus selecionados serem integrantes da Aliança Nacional Libertadora (ANL) para que fossem condenados.

A estigmatização, sob o rótulo de subversivos, dos que integravam a oposição ao regime fenômeno que se repetiria a partir de 1964 -, e a necessidade de alterar a legislação conforme os objetivos do governo, especialmente sob o argumento de garantir a ordem diante de ameaças comunistas, foram estratégias utilizadas pelo governo de Getúlio Vargas nessa fase. A edição da Lei de Segurança Nacional, em abril de 1935, que deslocou para uma justiça especial os crimes contra a segurança do Estado, foi o ícone da legalidade autoritária do período. Embora com inúmeras alterações no seu texto, a lei foi mantida após a queda do Estado Novo, em 1945 . Essa legislação ganharia especial atenção com o golpe de 1964, quando também serviu de base para o julgamento, pela justiça militar, dos opositores ao regime.

Implementado o golpe de 1964, com a adoção de medidas análogas às tomadas na ditadura do Estado Novo, o terreno que caberia ao Judiciário durante os vinte e um anos de ditadura militar foi fortemente assentado pelo AI-2. Com base nele Castello Branco nomeou, em 1965, cinco novos ministros para o Supremo Tribunal Federal (STF): Adalício Nogueira (sucedido por Xavier de Albuquerque, nomeado por Garrastazu Médici, por sua vez sucedido por Rafael Mayer, nomeado por Ernesto Geisel), Prado Kelly (sucedido por Thompson Flores, nomeado por Costa e Silva, por sua vez sucedido por Clovis Ramalhete, nomeado por João Figueiredo), Oswaldo Trigueiro (sucedido por Moreira Alves, nomeado por Ernesto Geisel), Aliomar Baleeiro (sucedido por Cunha Peixoto, nomeado por Ernesto Geisel, por sua vez sucedido por Alfredo Buzaid, nomeado por João Figueiredo) e Carlos Medeiros (sucedido por Eloy da Rocha, nomeado por Castello Branco, por sua vez sucedido por Soares Muñoz, nomeado por Ernesto Geisel).

Ao todo, de 1965 (quando foram nomeados os primeiros ministros pelo poder militar) até 1985, o último regime autoritário brasileiro foi responsável pela nomeação de trinta e dois ministros do Supremo Tribunal Federal. De 1985 até a promulgação da Constituição Federal de 1988, o

\footnotetext{
${ }^{1}$ As sucessivas legislações sobre segurança nacional no Brasil foram: Lei $\mathrm{n}^{\circ}$ 48, de 4 de abril de 1935; Lei $\mathrm{n}^{\circ} 1.802$, de 5 de janeiro de 1953; Decreto-Lei $n^{\circ}$ 314, de 13 de março de 1967; Decreto-Lei $n^{\circ}$ 898, de 29 de setembro de 1969; Lei $n^{\circ}$ 6.620, de 17 de dezembro de 1978, e Lei ${ }^{\circ}$ 7.170, de 14 de dezembro de 1983.
} 
primeiro civil, não eleito, a assumir o poder após os militares - José Sarney - nomeou mais cinco ministros.

Além disso, após a nomeação dos primeiros cinco ministros do STF, o Ato Institucional no 6, editado em 1969, extinguiu cinco vagas que possuíam ministros nomeados antes do período de exceção. Esses postos eram ocupados por Evandro Lins e Silva, Hermes Lima, Victor Nunes Leal e Antônio Gonçalves de Oliveira, todos nomeados por João Goulart, e Lafayette de Andrada, nomeado por João Linhares. Após o marco constitucional de 1988, permaneceram no Supremo Tribunal Federal nove ministros nomeados pelo regime militar: Rafael Meyer, Djaci Falcão, Oscar Corrêa (os três permaneceram até 1989), Francisco Rezek (permaneceu até 1990), Aldir Passarinho (permaneceu até 1991), Octavio Gallotti (permaneceu até 2000), Néri da Silveira (permaneceu até 2002), Moreira Alves e Sydney Sanches (permaneceram até 2003)².

\section{A APLICAÇÃO DA LEGALIDADE AUTORITÁRIA}

O regime autoritário brasileiro teve a preocupação de minimizar traços de ruptura ou descontinuidade entre o regime anterior e o recém-implantado regime de exceção. Além de lapidar, conforme seus objetivos, aspectos-chave da organização judiciária, como alteração de competências, formas de ingresso e composição dos tribunais superiores (todos, procedimentos enganchados nas estruturas preexistentes), o verniz que tentava amenizar a descontinuidade institucional recorreu fortemente à proclamação da validade do direito anterior - construído no período democrático. Alegações sobre a validade do direito preexistente coexistiam com a autoproclamação do poder militar como única fonte do direito (OSIEL, 1995, p. 512) e com a própria confecção vertiginosa da legalidade autoritária.

No caso do Judiciário, esses discursos serviam para fundamentar decisões que costuravam retalhos da legislação democrática com regras de exceção. Analisando o contexto autoritário de outros países latino-americanos, Barrera (2015, p. 330) afirma ter sido recorrente, pelos juízes, a adoção de uma “técnica” de interpretação do direito que compactava, em um mesmo corpo, normas de quaisquer origens, em uma clara preocupação em aparentar uma contiguidade não apenas do ordenamento, mas do próprio trabalho do Judiciário, pois os juízes continuavam aplicando o direito conforme a doutrina e a jurisprudência tradicionais. Esse propósito foi utilizado como "técnica”

\footnotetext{
${ }^{2}$ Foram considerados os ministros nomeados por Castello Branco, Costa e Silva, Garrastazu Médici, Ernesto Geisel e João Figueiredo. Caso se desconsiderem as nomeações realizadas por João Figueiredo, permaneceram no STF três ministros nomeados por militares, após a Constituição de 1988: Rafael Mayer, Djaci Falcão e Moreira Alves. Todos os decretos de nomeação, posse e aposentadoria estão disponíveis no endereço eletrônico do Supremo Tribunal Federal: $<$ http://stf.jus.br/portal/ministro/ministro.asp> (acesso em: 30 jan. 2016).
} 
que, de um lado, buscava ampliar o máximo possível a discricionariedade do poder de exceção e, de outro, manter a aparência de normalidade, confeccionando continuidades, em relação ao direito a ser aplicado e ao funcionamento institucional do Judiciário. Sob essa perspectiva, a jurisprudência do regime autoritário foi construída sob a base da doutrina do direito como fato, a qual estava amparada em uma particular interpretação do positivismo, denominada, por Nino (2010, p. 37), de positivismo ideológico. O direito teria validade e obrigatoriedade, e suas disposições deveriam ser aplicadas, necessariamente, pelos juízes, independentemente de conteúdos morais, desde que proveniente do Estado.

No mesmo sentido, Bobbio (1995, p. 137) também tece considerações sobre o positivismo como tratamento avalorativo, capaz de assumir o direito como fato, excluindo-se toda qualificação fundada em juízo de valor e que comporte a distinção do próprio direito em bom e mau, justo e injusto. Assim, o direito é aquele que efetivamente se manifesta na realidade histórico-social. Conduzindo-se por essa concepção, os juízes interpretariam, em igualdade de condições de legitimidade, normas oriundas de Estados de direito ou de exceção.

Embora essa estratégia já tivesse sido utilizada em outros períodos autoritários, em uma manifesta reiteração da história constitucional brasileira durante intervalos de ruptura ${ }^{3}$, o Judiciário brasileiro conduziu-se, durante o último período de exceção, conforme a teoria do direito como fato. Diversas demandas ajuizadas originalmente na justiça comum foram deslocadas para a justiça militar, conforme disposição dos atos institucionais que impedia a apreciação judicial da legalidade dos atos do poder militar. Esse encaminhamento à justiça militar era feito, não raro, por meio de despachos de juízes da justiça comum que, para tanto, deveriam reconhecer a validade das disposições dos atos institucionais. Essa anuência, pelos juízes, do dispositivo que impedia o acesso à justiça comum, caracteriza-se como uma clara interpretação do direto como fato, gerado por razões de Estado.

Exemplo desse comportamento é a decisão proferida pelo juiz estadual da Vara da Fazenda Pública do Estado do Rio Grande do Sul em dezembro de 1968. Na ação, a autora requeria a anulação de ato do Estado do Rio Grande do Sul que, com base no Ato Institucional no 1, a demitiu das funções de professora de ensino médio. Nas suas razões de decidir, o juiz estadual afirmou que “a espécie era demasiadamente simples, pois a apreciação dos fatos que determinaram a punição da autora, bem como da sua oportunidade ou conveniência, escapava ao controle do Poder Judiciário, por força de expressa disposição legal (art. $7^{\circ}, \S^{\circ}$, do AI n 1)” (RIO GRANDE DO SUL, 1968).

\footnotetext{
${ }^{3}$ Marques (2011) traz alguns exemplos interessantes sobre a jurisprudência do Tribunal de Segurança Nacional durante a ditadura varguista.
} 
Aplicou-se, então, a legislação que, de fato, existia à época, sem nenhuma consideração sobre seus conteúdos ou suas origens.

Na mesma linha, o Supremo Tribunal Federal, em um momento em que sua maioria já era nomeada pelos militares, também fundiu as normas existentes no Brasil na década de 60, em uma tentativa de conferir aparência de continuidade institucional. No caso, o STF deveria decidir qual legislação autoritária aplicar; ou seja, não se tratava de apreciar legislações de origens diversas, quanto à legitimidade de produção, mas de reconhecer e naturalizar a legalidade autoritária, novamente valendo-se da artimanha de utilizar o direito de fato como se legítimo fosse. Conforme referido pela própria Comissão Nacional da Verdade, em seu Relatório Final, o STF não apenas tratou a legalidade autoritária como legítima, como optou por aplicar a regra que não confrontava sua decisão com o poder de exceção, ainda que subvertendo a hierarquia da própria legalidade autoritária - presumindo-se que se pretendesse alguma lógica no sistema legal, o que não deixa de ser bastante questionável diante do pandemônio legislativo produzido pelo poder de exceção brasileiro (BARBOSA, 2010).

\begin{abstract}
Quando já composto, majoritariamente, por ministros nomeados pela ditadura, o STF foi chamado a pronunciar-se sobre a alteração promovida pelo artigo 118 da Constituição de 1967, nos autos do Mandado de Segurança no 18.973, ocasião em que negou a segurança, nos termos do voto do ministro relator Temístocles Cavalcanti, com a divergência dos votos dos ministros Evandro Lins, Hermes Lima e Victor Nunes Leal. Tal mandado de segurança foi impetrado por juízes federais substitutos, que arguiram o seu direito líquido e certo ao provimento do cargo efetivo de juízes federais, em razão de aprovação em concurso de provas e títulos, tal como exigido pela Constituição de 1967. Os impetrantes defendiam que o presidente da República não poderia utilizar-se de livre nomeação para, nos termos do AI2, prover o cargo de juízes federais, uma vez que a Constituição de 1967, então em vigência, demandava requisito específico de aprovação em concurso de provas e títulos e gozava de superioridade hierárquica em relação ao AI-2 e a Lei n ${ }^{0}$ 5.010/1966. A despeito do argumentado, o STF decidiu, em 22 de junho de 1968, por maioria, que "o advento da Constituição, e a adoção de um sistema novo, não justificaria a interrupção da aplicação de um processo apoiado em um texto legal que tem o seu fundamento no ato institucional, aprovados esses atos pela Constituição que os revigorou”. Ou seja, decidiu pela prevalência do AI-2 e da Lei no 5.010/1966, no caso concreto, em detrimento da Constituição de 1967, desconsiderando, assim, os requisitos hermenêuticos pertinentes à supremacia e a vigência constitucional. (COMISSÃO NACIONAL DA VERDADE, 2014, p. 346)
\end{abstract}

Nessa decisão, os votos dissidentes foram proferidos por três ministros não nomeados pelos militares (Evandro Lins, Hermes Lima e Victor Nunes Leal) e que, junto com Gonçalves de Oliveira, tiveram suas vagas extintas dez meses após essa decisão, com o advento do Ato Institucional $n^{\circ}$ 6, em 1969. 


\section{O PROJETO CONSTITUCIONAL AUTORITÁRIO}

Ao discorrer sobre a história do constitucionalismo latino-americano, Gargarella (2014, p. 31) defende que as constituições mais longevas da região se basearam na fórmula $a$ Cruz $e a$ espada, que unia um elitismo político baseado na convicção de que as novas sociedades deveriam se organizar em torno de um projeto moral homogêneo (tradicionalmente consubstanciado na Igreja Católica, embora não exclusivamente) com a certeza de que seria necessário recorrer à força para impor a ordem.

O uso da força era esperado e decorreria naturalmente da necessidade de ordenar uma sociedade pouco educada e que poderia resistir à implementação do projeto moral ${ }^{4}$. A fórmula “elitismo político e perfeccionismo moral” resumiria essa tradição. Interessante destacar que o elitismo político estaria associado a dois elementos-chave: obedeceria a um reclame ontológico, que acreditaria na existência de verdades políticas que deveriam conduzir a vida pública, ao passo que, epistemologicamente, acreditava que essas verdades seriam descobertas ou implementadas pelas pessoas mais capacitadas ${ }^{5}$.

O prólogo do primeiro Ato Institucional afirma que os chefes da revolução vitoriosa, graças à ação das Forças Armadas, representam o povo e em seu nome exercem o Poder Constituinte. Segue afirmando que o Ato Institucional fora editado pelos Comandantes-em-Chefe do Exército, da Marinha e da Aeronáutica e se destinava a assegurar ao novo governo instituído os meios indispensáveis à reconstrução econômica, financeira, política e moral do Brasil (BRASIL, 1964, p. 3.193). Os chefes das forças armadas, então, seriam os detentores da capacidade de

\footnotetext{
${ }^{4}$ Esse modelo constitucional conservador da cruz e da espada é antigo na América Latina, de forma que Gargarella (2014, p. 32) menciona que as primeiras constituições a contemplarem esse modelo em seus textos foram as Constituições do Chile de 1823 e de 1833, as da Colômbia de 1843 e de 1886, a do Equador de 1969, a do México de 1843 e a do Peru de 1839.

${ }^{5}$ Um bom exemplo da adoção desse pensamento conservador no Brasil pode ser ilustrado pela manifestação doutrinária proferida por Miguel Reale sobre o golpe de 1964: "O que nos deve preocupar é sobretudo o perigo de se revalorizar, por contraste, aquele passado pequenino de desordem e de demagogia que a Revolução de março oportunamente destruiu: aos chefes do Governo Revolucionário cabia, efetivamente, atender às exigências substanciais do país" (REALE, 1977, p. 23). Declaração semelhante foi dada por Manoel Gonçalves Ferreira Filho, que, ao ignorar o contexto de exceção pelo qual passava o Brasil, tratou de se referir aos militares que estavam no poder como se o tivessem assumido legitimamente: "É necessário, por isso, determinar um modelo em que a maioria, o povo, selecione em todas as camadas sociais os mais capazes de governar, confiando-lhe o poder. Assim, povo e poder democrático se interpenetrarão, estabelecendo um governo do povo, pelo povo e para o povo.” (FERREIRA FILHO, 1974, p. 79) O próprio processo de anistia política brasileiro foi marcado por esse modelo conservador, cuja declaração do deputado Carlos Sant'Anna, ao comentar sobre a Lei ${ }^{\circ}$ 6.683/79, que seria promulgada no dia seguinte, é uma boa ilustração: "Concluirei dizendo apenas que a anistia e a abertura não se consumam num ato; que a anistia e a abertura representam um processo. O importante é que possamos obter amanhã aquela anistia possível a esta Casa, da forma que o Presidente oferece ao povo brasileiro" (BRASIL, 1979, p. 1.644). Sobre a tentativa de amalgamar a ideia de esquecimento às graves violações de direitos humanos perpetradas por agentes públicos mediante o instituto da anistia, ver SCHINKE, Vanessa Dorneles. Anistia e esquecimento: a pá de cal do Congresso Nacional, a anistia pactuada do Judiciário e o horizonte de expectativa. Rio de Janeiro: Lumen Juris, 2015.
} 
conduzir a nação brasileira a um novo patamar (moral, econômico, financeiro e político). Paralelamente, quanto à espada, na medida em que os opositores ao regime de exceção convertiamse em inimigos internos, etiquetados como subversivos ou terroristas, o uso da força apresentava-se como providência necessária e naturalmente decorrente da necessidade de expurgar os que se opunham à implementação do projeto propugnado pela Doutrina da Segurança Nacional.

Em estudo dedicado à influência da ideologia da segurança nacional na América Latina, Comblin (1980, p. 44) revela que a ideia de guerra total, definidora da própria condição humana para essa ideologia, comporta três conceitos que estariam na base dessa doutrina: a guerra generalizada, a guerra fria e a guerra revolucionária. De qualquer forma, conforme Pereira (2010, p. 53), não haveria necessidade de diferenciar guerra revolucionária, guerrilha, subversão, terrorismo e guerra de libertação nacional, pois o que estaria por trás desses movimentos seria sempre o processo de uma guerra revolucionária.

No Brasil, a Escola Superior de Guerra (ESG) foi fundada em 1949, inspirada na similar estadunidense National War College e sob a jurisdição do Estado-Maior das Forças Armadas. De 1954 a 1964, a ESG desenvolveu uma teoria autoritária de direita para intervenção no processo político nacional. A partir de 1964, a ESG funcionaria também como formadora de quadros para ocupar funções nos sucessivos governos. Entre seus subprodutos, além da ideologia anticomunista, que se traduziu na Doutrina da Segurança Nacional, destaca-se a criação do Serviço Nacional de Informações (SNI), por Golbery do Couto e Silva (SANTOS, 2010, p. 24).

Logo após o golpe de 64, a reprodução da mentalidade da Segurança Nacional nas escolas militares superou os ensinamentos referentes a outras formas de guerra. Stepan (1973, p. 57) afirma que, a partir de 1965, 50\% do tempo de formação foi dedicado ao ensino da guerra revolucionária nas escolas militares, embora dez anos antes, em 1956, não houvesse nenhum curso sobre comunismo ou guerrilha na Escola de Comando e de Estado-Maior do Exército do Brasil (ECEME). Posteriormente, em 1966, os cursos apresentavam 222 horas-aula sobre segurança interna, 129 horas sobre guerrilhas e apenas 24 horas sobre a guerra convencional, entre Estados.

Quanto à naturalização dessa ideologia, Ernani Sátyro - homem de confiança da cúpula militar que fora ministro nesse tribunal - transcreve, em um livro sobre a jurisprudência do Superior Tribunal Militar, diversas decisões por ele proferidas ${ }^{6}$. Além de naturalizar a legalidade autoritária,

\footnotetext{
${ }^{6}$ Ernani Sátyro foi líder do governo Costa e Silva (entre 1967 e 1968) na Câmara dos Deputados. Em 1969 renunciou ao cargo de deputado para acolher a nomeação para o Superior Tribunal Militar. Em 1970, foi nomeado governador da Paraíba por Garrastazu Médici. Ocupou o cargo de deputado federal por oito vezes, entre os anos de 1945 e 1986 . Em 1979, participou ativamente do processo que resultou na Lei ${ }^{\circ}$ 6.683/79, tendo sido escolhido, pelo governo, relator do projeto de anistia. Em um dos seus discursos proferidos durante os debates sobre a anistia, subiu à tribuna para afirmar que o Brasil não possuía tradição de conceder anistia ampla, geral e irrestrita, de forma que o projeto de anistia
} 
tais decisões são descritas detalhadamente, a fim de, segundo o autor, valorizar policiais, procuradores, advogados e juízes empenhados nos feitos, e de retratar fidedignamente as graves situações que, a seu juízo, então ameaçavam a segurança nacional, corriqueiramente agredida pela subversão, o terrorismo e outras formas ilegais de contestação do regime e de ameaça aos mais legítimos e sagrados interesses nacionais (SÁTYRO, 1977, p. 9).

A doutrina da segurança nacional foi capaz de unir o viés de elitismo político, mediante a pregação de uma crença nos objetivos nacionais, com a imposição da força, como instrumento necessário para garantir que tais finalidades fossem alcançadas. Ao tratar da segurança nacional na América Latina, Pessoa (1971, p. 243) realiza uma diferenciação entre o direito da segurança nacional e o direito à segurança nacional, deixando claro que o elemento ideológico é inseparável da força que o viabiliza:

O direito da segurança nacional, em sentido estrito, é o conjunto de normas jurídicas, codificadas ou não, que objetivamente visam a conferir ao Estado a manutenção da ordem sócio-político-jurídica, indispensável à salvaguarda dos valores ou características nacionais, sob a cominação de penas, se ocorrerem atos criminosos que a ofendam ou ameacem ofendê-la. [...] Aparentemente, no direito da segurança nacional, a vítima e o juiz se confundem numa só pessoa - o Estado. Entretanto, cabe ressalvar que o Poder Judiciário, pela via das garantias constitucionais que o robustecem, elimina aquela confusão. (PESSOA, 1971, p. 243)

Note-se que o esforço teórico para legitimar a arbitrariedade estatal condensa a necessidade de proteção dos valores nacionais à cominação de penas, retomando a afirmação de Gargarella (2014) de que a força é instrumento indispensável para a garantia da ordem - dentro da concepção do modelo constitucional conservador latino-americano. Diante disso, considerando a narrativa constitucional brasileira, a adoção de medidas que tentam aparentar normalidade institucional do Judiciário (durante períodos de exceção) não é suficiente para apagar traços de comportamento que vinculam esse espaço institucional à arbitrariedade dos períodos. O Judiciário caracterizou-se como um espaço estratégico para a implementação e a permanência do projeto autoritário.

\section{PERMANÊNCIAS E METAMORFOSES AUTORITÁRIAS DO JUDICIÁRIO NO PERÍODO PÓS-DITATORIAL}

Uma vez superada a moldura institucional mais evidente das ditaduras militares e tendo sido operada a transição política rumo à democracia, é preciso aguçar o olhar na direção das permanências e metamorfoses autoritárias, tendo em vista especialmente a atividade jurisdicional.

oferecido pelo governo se moldava perfeitamente à história brasileira. BRASIL. Parecer n. 78/79-CN. Diário do Congresso Nacional. Seção Conjunta. Brasília: Distrito Federal, 18 ago. 1979. p. 1.574. Para mais detalhes sobre os debates parlamentares durante o processo legislativo que resultou na Lei nº 8.666/93, ver SCHINKE (2015b). 
Claro está que, para avançar nesse necessário exercício investigativo, é crucial afastar os véus de opacidade sobre o papel desse Poder ao longo das ditaduras com as quais conviveu aparentemente sem maiores sacrifícios e contradições, mister que justifica o esforço parcial até aqui realizado ${ }^{7}$.

A par da ausência de depurações administrativas no corpo do Poder Judiciário após o regime autoritário, seja em relação ao pessoal integrante do aparato burocrático, seja em relação aos próprios magistrados (o que foi uma característica especialmente intensa no caso brasileiro), importa aqui destacar a manutenção no regime democrático de uma expectativa moralizante a respeito da atuação jurisdicional combinada com sua presença cada vez maior nas funções de mediação institucional e social.

Para um diagnóstico coerente com os que poderiam ser apontados como os cânones democráticos mais básicos, sejam eles relativos à soberania popular ou ao espaço conferido à participação da sociedade civil organizada e à permeabilidade às demandas populares, não basta partirmos apenas das definições conceituais reservadas ao papel do Poder Judiciário em um Estado de direito. É preciso problematizar suas continuidades históricas, sua estrutura elitizante, hierárquica e pouco permeável ao exercício democrático, o que assume cores especiais no contexto latino-americano (ZAFFARONI, 1995).

Como bem lembra Cittadino (2004), em um país como o Brasil (e o mesmo se poderia dizer da Argentina) dificilmente se pode invocar a existência de uma comunidade de valores que possa ser perscrutada pela inteligência e sensibilidade superiores de algum magistrado, ou que esteja afinada com alguma tradição constitucional. Ao contrário do que ocorre, por exemplo, nos Estados Unidos da América, a história constitucional brasileira e a argentina são permeadas por rupturas e continuidades que não autorizam a pressuposição quanto à existência de algum tipo de tradição. Tampouco é factível supor-se uma comunidade ética de valores compartilhados no contexto de sociedades profundamente marcadas pela desigualdade e pela assimetria nas relações de poder (se é que seria possível fazê-lo em relação a qualquer sociedade contemporânea), sem falar no intenso pluralismo que as caracterizam. Para análises que simplesmente buscam transferir esse modelo de uma atividade judicial calcada na quase esotérica habilidade dos juízes para traduzir os valores ou a moral da sociedade falta, sobretudo, fazer um finca-pé nas realidades históricas e políticas para as quais se voltam, especialmente quando o foco é a região latino-americana, notoriamente autoritária e desigual.

Em contextos assim, o compromisso maior e necessário do Poder Judiciário deve ser, de um lado, o de concretizar a constituição a partir dos seus próprios marcos republicanos, abrindo

\footnotetext{
${ }^{7}$ Além do presente artigo, importa citar especialmente: SCHINKE (2015) e SILVA FILHO (2015).
} 
mão da busca de um denominador moral objetivo que esteja para além ou para aquém da referência constitucional, e controlando com especial atenção os seus próprios arroubos ativistas, e, de outro, a abertura e a permeabilidade aos grupos sociais populares organizados voltados a pautas emancipatórias de diminuição das desigualdades históricas e ao respeito e ampliação dos direitos fundamentais. Como bem adverte Maus (2000, p. 187),

[q]uando a justiça ascende ela própria à condição de mais alta instância moral da sociedade, passa a escapar de qualquer mecanismo de controle social - controle ao qual normalmente se deve subordinar toda instituição do Estado em uma forma de organização política democrática. No domínio de uma Justiça que contrapõe um direito "superior", dotado de atributos morais, ao simples direito dos outros poderes do Estado e da sociedade, é notória a regressão a valores pré-democráticos de parâmetros de integração social.

Não se trata de negar ao Judiciário a faculdade de que exerça a interpretação da lei ou de querer regressar a parâmetros positivistas ou de literalidade ${ }^{8}$, especialmente em um marco constitucional principiológico, mas sim que se abstenha de ostentar as categorias objetivas da moralidade social e confundir interpretação com subjetivismo ou decisionismo. Autonomia e independência judiciais não devem ser compreendidas como uma carta branca subjetiva àquilo que o juiz ou a instituição judicial, em seus controles altamente verticalizados, entendem como correto. Dado o seu histórico de complacência autoritária, é imprescindível que se opere uma democratização na própria estrutura administrativa do Poder Judicial $^{9}$ e em relação à sua atividade, ampliando os controles sociais e democráticos, buscando-se criar verdadeiras pontes de diálogos e construção entre a magistratura e os movimentos sociais, sem o que, esvaem-se a legitimidade e a soberania popular.

Todavia, o que se pode mais notar no horizonte judicial pós-ditatorial, especialmente o brasileiro, não é propriamente uma abertura ao diálogo ou à construção hermenêutica aberta da constituição (HÄBERLE, 1997), mas sim uma tendência de criminalização dos movimentos sociais e de manutenção do tradicional esquema individualista proprietário da modernidade capitalista, sobejamente impulsionada com cores violentas e autoritárias pelas ditaduras civis-militares na

\footnotetext{
${ }^{8}$ Para uma reflexão sobre o caráter construtivo da hermenêutica jurídica e a impossibilidade científica de uma interpretação meramente reprodutiva, ver SILVA FILHO, 2006.

${ }^{9}$ A esse respeito, ver o sucinto artigo de Escrivão Filho (2015, p. 39-40) sobre o caráter centralizador, verticalizante e oligárquico da estrutura judicial no Brasil, no qual são citados, por exemplo: a inexistência do sufrágio direto exercido pelos magistrados e servidores para a escolha dos presidentes dos tribunais de justiça; órgãos de corregedoria controlados pelos tribunais e conformadores de uniformidades condizentes com o padrão político e ideológico adotado; presença diminuta de representantes das minorias sociais na composição dos quadros (mulheres, negros, indígenas, LGBT, etc.); controle externo limitado, tímido, tardio, incompleto e claudicante. Ainda relativamente ao processo de escolha dos juízes da instância judicial nacional mais elevada, o autor aponta para uma diferença nos critérios de composição dos juízes da Corte Suprema argentina e nos do Supremo Tribunal Federal no Brasil. Enquanto naqueles se prevê expressamente o compromisso do futuro magistrado do Tribunal com os direitos humanos (em acordo com o Decreto Presidencial n. 222/2003), exemplo também presente na Constituição boliviana de 2009, nestes nada se menciona sobre a necessidade de tal compromisso.
} 
América Latina. Em um cenário de crescente protagonismo judicial no campo da política e das lutas sociais por direitos é vital que sejam ampliados, no campo judicial, os espaços de participação democrática e de controle, ou então que o modelo constitucional que favorece o protagonismo judicial seja revisto.

É necessário, pois, que seja posicionada e reconhecida a seguinte questão:

[...] é possível o exercício democrático com um Judiciário conservador, incapaz, portanto, de assimilar formas participativas de mediação para os conflitos e para o reconhecimento de novos direitos instituídos permanentemente em uma sociedade plural? Esta é sem dúvida a questão candente hoje, em nosso país, quando se coloca em causa o problema de sua democratização e se identifica no Judiciário a recalcitrância que é social e teórica para a realização de mudanças sociais, conferindo à regulamentação jurídica das novas instituições o seu máximo potencial de realização das promessas constitucionais de reinvenção democrática. (SOUSA JUNIOR, 2011, p. 61)

\section{CONSIDERAÇÕES FINAIS}

O crescimento do interesse pela dimensão civil das ditaduras latino-americanas decorre, por exemplo, da desconfiança de que nem mesmo uma legalidade autoritária, por si só, seria suficiente para sustentar longos períodos de exceção - ao menos, não sem uma grande margem de risco para o poder de exceção. As nuanças que decorrem de “como” a própria legalidade forjada pelos militares foi aplicada conduz à reflexão sobre o espaço ao qual caberia essa tarefa, a forma como foi feito e as suas conformações institucionais, moldadas conforme interesses autoritários, durante esses períodos.

A literatura que se debruça sobre essas questões expõe algumas estratégias, em relação ao Judiciário, adotadas pelos regimes autoritários. Essas estratégias tinham a finalidade de aparentar uma normalidade institucional, contribuindo para manter a imagem internacional dos países, captar investimentos, criminalizar e afastar opositores e, se não aliciou, serviu para não afastar setores mais conservadores da sociedade civil. Diante das consequências e da forma como o Judiciário atuou nesses dois contextos autoritários, impõe-se o aprofundamento dos estudos sobre as funções desempenhadas por esse espaço durante períodos de ruptura institucional. Essas pesquisas podem contribuir para esclarecer que determinadas funções do Judiciário, moduladas para um contexto autoritário, permanecem ativadas em um regime democrático.

Mais especificamente no caso brasileiro, os movimentos de redemocratização depositaram esperanças emancipatórias no exercício jurisdicional diante de uma constituição generosa em princípios sociais, garantias e declarados ânimos de mudança em direção a uma sociedade mais 
justa e igualitária. Contudo, não basta sobrepor ao desenho antigo um desenho novo, como se estivéssemos tratando de um palimpsesto ${ }^{10}$.

As tentativas de mero apagamento das violências, injustiças e erros do passado acabam por contribuir para a sua persistência, ainda que velada. O caminho seguro, embora despido de garantias, para o aprofundamento democrático e a democratização do Poder Judiciário, é o conhecimento das suas práticas, padrões e estruturas - autoritários, por vezes silenciosos, em muitos casos passivos, mas sempre coniventes com o aprofundamento da desigualdade, da violência e do arbítrio.

\section{REFERÊNCIAS}

AGUILAR, Paloma. Judiciary Involvement in Authoritarian Repression and Transitional Justice: The Spanish Case in Comparative Perspective. International Journal of Transitional Justice, 2013, v. 7, n. 2, p. 245-266.

BARRERA, Leticia. ¿Ruptura o continuidad? A propósito de la transición de la Corte Suprema de la dictadura a la democracia. In: ¿Usted también doctor? Complicidad de jueces, fiscales y abogados durante la dictadura. Buenos Aires: Siglo Veintiuno Editores, p. 327-344, 2015.

BARROS, Robert. Courts out of context: authoritarian sources of judicial failure in Chile (19731990) and Argentina (1976-1983). In: GINSBURG, Tom; MOUSTAFA, Tamir (Ed.). Rule by Law. The Politics of Courts in Authoritarian Regimes. New York: Cambridge University Press, 2008.

BERCOVICI, Gilberto. Constituição e política: uma relação difícil. Lua Nova, São Paulo, n. 61, 2004, p. 5-24.

. O poder constituinte do povo no Brasil: um roteiro de pesquisa sobre a crise constituinte. Lua Nova, São Paulo, n. 88, 2013, p. 305-325.

BERTOMEU, Juan González. Los doce apóstoles: la Corte Suprema y sus jueces en la ditadura. In: ¿Usted también doctor? Complicidad de jueces, fiscales y abogados durante la dictadura. Buenos Aires: Siglo Veintiuno Editores, p. 94-110, 2015.

BOBBIO, Norberto. O Positivismo Jurídico: Lições de filosofia do direito. São Paulo: Ícone, 1995.

BOHOSLAVSKY, Juan Pablo; GARGARELLA, Roberto. El rol de la Corte Suprema: aportes repetidos y novedosos. In: ¿Usted también doctor? Complicidad de jueces, fiscales y abogados durante la dictadura. Buenos Aires: Siglo Veintiuno Editores, p. 77-91, 2015.

BRASIL. Ato Institucional $\mathrm{n}^{0}$ 2, de 27 de outubro de 1965. Diário Oficial da União, Brasília, DF, 27 out. 1965, Seção 1, p. 11.017. Retificação publicada no Diário Oficial da União, Brasília, DF, 28 out. 1965, Seção 1, p. 11.353.

\footnotetext{
${ }^{10}$ Antigo pergaminho que era reutilizado duas ou três vezes e mantinha o registro das escritas anteriores, que, embora não identificadas claramente a olho nu, poderiam ser decifradas a partir de técnicas especiais (N. do A.).
} 
Comando Supremo da Revolução. Ato Institucional de 9 de abril de 1964. Diário Oficial da União, Brasília, DF, 9 abr. 1964, Seção 1, p. 3.193.

1, p. 11.736 .

. Decreto 16 nov. 1965. Diário Oficial da União, Brasília, DF, 17 nov. 1965, Seção 1, Parte

. Discussão, em turno único, do Projeto de Lei n. 14, de 1979-CN, que “concede anistia e dá outras providências”, tendo Parecer, sob n. 78, de 1979-CN, da Comissão Mista, favorável nos termos do substitutivo que oferece. Diário do Congresso Nacional, Seção Conjunta, 22 ago. 1979, p. 1.644.

. Mensagem apresentada ao Poder Legislativo em 3 de maio de 1937, pelo Presidente da República, Getúlio Dornelles Vargas. Rio de Janeiro: Imprensa Nacional, 1937. Disponível em: $<$ http://brazil.crl.edu/bsd/bsd/u1277>. Acesso em: 21 jan. 2015.

. Parecer n. 78/79-CN. Diário do Congresso Nacional, Seção Conjunta, Brasília, DF, 18 ago. 1979, p. 1.574 .

. Relatório/Comissão Nacional da Verdade. Brasília: CNV, 2014, v. I.

CAMPOS, Francisco. O Estado nacional e suas diretrizes. Brasília: Imprensa Nacional, 1937a.

. O Estado nacional: sua estrutura, seu conteúdo ideológico. 1937b. Disponível em: <ebooksbrasil.org/eLibris/chicocampos.html>. Acesso em: 20 jan. 2015.

CAMPOS, Francisco. Os problemas do Brasil e as grandes soluções do novo regime. Brasília: Imprensa Nacional, 1938.

CITTADINO, Gisele. Poder Judiciário, ativismo judicial e democracia. Alceu (PUCRJ), v. 5, n. 9, p. 105-113, jul./dez. 2004.

COMBLIN, Joseph. A ideologia da segurança nacional: o poder militar na América Latina. 2. ed. Rio de Janeiro: Civilização Brasileira, 1978.

DÍAS-ASENSIO, Juan Antonio Mayoral. ¿Por qué los autócratas limitan judicialmente su poder? Un análisis comparado del establecimiento de altos tribunales en regímenes autoritarios. Instituto Universitario Europeo. Revista de Estudios Políticos (nueva época), n. 158, Madrid, out./dez., p. 4174, 2012.

ESCRIVÃO FILHO, Antonio. Do acesso ao controle judicial: os movimentos sociais e a luta pelos direitos humanos em face da expansão política da justiça. In: ESCRIVÃO FILHO, Antonio et al. (Org.). Justiça e direitos humanos: perspectivas para a democratização da justiça. Curitiba: Terra de Direitos, 2015, p. 28-61.

ETCHICHURY, Horacio Javier. Orden, ficción y liberalismo: los derechos sociales em la Corte. In: ¿Usted también doctor? Complicidad de jueces, fiscales y abogados durante la dictadura. Buenos Aires: Siglo Veintiuno Editores, p. 111-128, 2015.

FERREIRA FILHO, Manoel Gonçalves. A democracia possível. 2. ed. São Paulo: Saraiva, 1974.

Revista da Faculdade de Direito - UFPR, Curitiba, vol. 61, n. 2, maio/ago. 2016, p. 41 - 59 
GABRIELLI, Adolfo. La Corte Suprema de Justicia y la opinión pública: 1976-1983. Buenos Aires: Abeledo-Perrot, 1986.

GARGARELLA, Roberto. La lectura mayoritaria del Estado de derecho. In: Cuaderno Gris, n. 9, 2007.

. La sala de máquinas de la Constitución: dos siglos de constitucionalismo en América Latina (1810-2010). Buenos Aires: Katz Editores, 2014.

; MURILLO, María Victoria; PECHENY, Mario. Introducción: origen y propósitos de este libro. In: GARGARELLA, Roberto; MURILLO, María Victoria; PECHENY, Mario. Discutir Alfonsín. Buenos Aires: Siglo XXI, 2010.

GINZBURG, Tom. Judicial Review in New Democracies: Constitutional Courts in Asian Cases. New York: Cambridge University Press, 2003.

GROISMAN, Enrique. La Corte Suprema de justicia durante la dictadura (1976-1983). Buenos Aires: CISEA, 1987.

HÄBERLE, Peter. Hermenêutica constitucional: a sociedade aberta dos intérpretes da Constituição - contribuição para a interpretação pluralista e "procedimental” da Constituição. Trad. Gilmar Ferreira Mendes. Porto Alegre: Sergio Antonio Fabris, 1997.

HELMKE, Gretchen. Courts under Constraints. Judges, Generals and Presidents in Argentina. Cambridge: Cambridge University Press, 2005.

HILBINK, Lisa. The Origins of Positive Judicial Independence. World Polictics, 64(4), 2012, p. 587-621.

KEITH, Linda. Political Repression, Courts and the Law. Philadelphia: University of Pennsylvania Press, 2012.

LANERO, Mónica. Una milícia de la justicia (1936-1945). Madrid: Centro de Estudios Constitucionales, 1996.

LASTRA, Arturo Pellet. Historia política de la Corte Suprema 1930-1990. Buenos Aires: Ad Hoc, 2001.

MARQUES, Raphael Peixoto de Paula. Repressão política e usos da constituição no governo Vargas (1935-1937): a segurança nacional e o combate ao comunismo. 2011. 218 f. Dissertação (Mestrado em Direito) - Universidade de Brasília, 2011.

MATUS, Alejandra. El libro negro de la justicia chilena. Barcelona: Planeta, 2000.

MAUS, Ingeborg. Judiciário como superego da sociedade - o papel da atividade jurisprudencial na “sociedade órfã”. Trad. Martonio Lima e Paulo Albuquerque. Novos Estudos, n. 58, p. 183-202, nov. 2000.

NINO, Carlos. Introdução à análise do direito. São Paulo: Editora WMF Martins Fontes, 2010. 
OLIVEIRA, María José. Poder Judicial y dictadura. El caso de la morgue. Buenos Aires: CELS Editores del Puerto, 2011.

OSIEL, Mark. Dialogue with Dictators: Judicial Resistance in Argentina and Brazil. Law and Social Inquiry, 20(2), 1995, p. 481-560.

PEREIRA, Anthony. Ditadura e repressão: o autoritarismo e o estado de direito no Brasil, no Chile e na Argentina. São Paulo: Paz e Terra, 2010.

PESSOA, Mário. O direito da segurança nacional. Rio de Janeiro: Biblioteca do Exército, 1971.

PINHEIRO, Paulo Sérgio. Estratégias da ilusão: a Revolução Mundial e o Brasil (1922-1935). São Paulo: Companhia das Letras, 1991.

REALE, Miguel. Da revolução à democracia. 2. ed. São Paulo: Convívio, 1977.

RIO GRANDE DO SUL. Ação Ordinária $n^{\circ}$ 80.047. Juízo de Direito dos Feitos da Fazenda Pública. Comarca de Porto Alegre. Requerido: Estado do Rio Grande do Sul. Juiz: Hermann Homem de Carvalho Roenick. Julgado em 30 dez. 1968. Fonte: Arquivo Judicial Centralizado do Rio Grande do Sul.

SANTOS, Roberto Lima. Crimes da ditadura militar - responsabilidade internacional do Estado brasileiro por violação aos Direitos Humanos. Porto Alegre: Nuria Fabris, 2010.

SÁTYRO, Ernani. Direito penal militar e segurança nacional: acórdãos, votos e despachos. Brasília: Senado Federal, 1977.

SCHINKE, Vanessa Dorneles. Anistia e esquecimento: a pá de cal do Congresso Nacional, a anistia pactuada do Judiciário e o horizonte de expectativa. Rio de Janeiro: Lumen Juris, 2015b.

Judiciário e autoritarismo: regime autoritário (1964-1985), democracia, usos e abusos da memória institucional. 2015. 366 f. Tese (Doutorado em Direito). Faculdade de Direito da Pontifícia Universidade Católica do Rio Grande do Sul, Porto Alegre, 2015.

SEELAENDER, Airton Lisle Cerqueira Leite. História constitucional brasileira. In: TAVARES, André R.; DIMOULIS, Dimitri; ROTHENBURG, Walter C. (Org.). Dicionário Brasileiro de Direito Constitucional. São Paulo: Saraiva, 2007.

SILVA FILHO, José Carlos Moreira da. Hermenêutica Filosófica e Direito - o exemplo privilegiado da boa-fé objetiva no direito contratual. 2. ed. rev. ampl. Rio de Janeiro: Lumen Juris, 2006.

Justiça de Transição - da ditadura civil-militar ao debate justransicional - direito à memória e à verdade e os caminhos da reparação e da anistia no Brasil. Porto Alegre: Livraria do Advogado, 2015.

SOUSA JUNIOR, José Geraldo de. Direito como liberdade - o Direito achado na Rua. Porto Alegre: Sergio Antonio Fabris, 2011. 
STEINWEIS, Alan; RACHLIN; ROBERT. The Law in Nazi Germany: Ideology, Opportunism and the Perversion of Justice. New York: Berghahn Books, 2013.

STEPAN, Alfred. Rethinking military politics: Brazil and the Southern Cone. New Jersey: Princeton University Press, 1988.

. The new professionalism of internal warfare and military role expansion. Authoritarian Brazil, p. 47-65, 1973.

SUPREMO TRIBUNAL FEDERAL. Recurso de habeas corpus $n^{\circ} 26.330$, 1937. Disponível em: <www.stf.jus.br>. Acesso em: 20 jan. 2015.

TRIBUNAL DE SEGURANÇA NACIONAL. Autos do Processo $n^{\circ} 1$-A. Réus: João Mangabeira. Pacientes: João Mangabeira, Domingos Velasco, Abguar Bastos, Octavio da Silveira e Abel Chermont. Relator: Juiz Lemos Bastos. 1937.

Relatório dos trabalhos realizados desde a sua instalação até 31 de dezembro de 1937. Rio de Janeiro: Imprensa Nacional, 1938.

ZAFFARONI, Eugenio Raúl. Poder Judiciário: crise, acertos e desacertos. São Paulo: Revista dos Tribunais, 1995.

\title{
JUDICIARY AND AUTHORITARIAN REGIME: DEMOCRACY, CONSTITUTIONAL HISTORY AND AUTHORITARIAN STAYS
}

\begin{abstract}
This paper analyzes the procedures adopted by the civilian-military dictatorship in Brazil (19641985) in relation to the judiciary. Its corporate purpose is to identify strategies used by the judiciary in order to alleviate impressions of discontinuities or institutional abnormalities. To that end, it makes the analysis from two interpretive themes: the authoritarian stays and speeches created to support the authoritarian project. In the face of authoritarian legality, it argues that the judiciary has adopted the theory of law and fact in order to obscure the break with the rule of law, using without distinction Institutional Acts, an imposed Constitution and laws from the previous democratic period. By analyzing national security doctrine, it projects the similarity between the narrative constructed by the judiciary and the conservative Latin American model, and also brings elements of the Brazilian constitutional history, identifying historical repetitions in relation to the roles played by the judiciary in different authoritarian contexts. Finally, it points to some authoritarian continuities of the Brazilian judiciary in the post-dictatorial period.
\end{abstract}

\section{KEYWORDS}

Judiciary. Authoritarian regime. Democracy. Authoritarian stays. 